\title{
Design and Development of High School Artificial Intelligence Textbook Based on Computational Thinking
}

\author{
Yanfang Yu, Yuan Chen \\ Hangzhou Zhejiang Radio and Television University, Hangzhou, China \\ Email: qzddyyf@163.com
}

How to cite this paper: Yu, Y.F. and Chen, Y. (2018) Design and Development of High School Artificial Intelligence Textbook Based on Computational Thinking. Open Access Library Journal, 5: e4898. https://doi.org/10.4236/oalib.1104898

Received: September 10, 2018

Accepted: September 27, 2018

Published: September 30, 2018

Copyright $(92018$ by authors and Open Access Library Inc.

This work is licensed under the Creative Commons Attribution International License (CC BY 4.0).

http://creativecommons.org/licenses/by/4.0/

\section{(c) (i) Open Access}

\begin{abstract}
Big data and deep learning technology have once again set off a boom in artificial intelligence. Artificial intelligence has been a major development strategy in many countries. The Chinese government has also written this into the "13th Five-Year Plan", and the Ministry of Education has also launched with the reform measures for artificial intelligence education, the deep integration of "artificial intelligence + education" has been opened. In this context, China's artificial intelligence disciplines and professional construction have set off a major reform storm from colleges to basic education. The revision of this high school artificial intelligence textbook was carried out in this context. The biggest feature of this high school artificial intelligence textbook revision is the integration of computational thinking into the core literacy design. Computational thinking is an indispensable ability of learners in the 21 st century. As a typical "digital aboriginal", high school students must have computational thinking in order to cope with the challenges brought about by the rapid changes in social technology in the future. At present, all developed countries have incorporated computational thinking into national curriculum standards. China has also written computational thinking into national curriculum standards and listed it as one of the core literacies of information technology disciplines.
\end{abstract}

\section{Subject Areas}

Artificial Intelligence, Education

\section{Keywords}

Artificial Intelligence, Computational Thinking, Core Literacy, Textbook Design 


\section{Introduction}

In July 2017, the "New Generation Artificial Intelligence Development Plan" issued by the State Council clearly defined the strategic goal of "three-step" of China's new generation of artificial intelligence, and proposed six key tasks of each participant, and also issued resources: Configure the program and develop safeguards to ensure implementation of the development plan. And it proposed: the implementation of the national intelligence education project, the establishment of artificial intelligence related courses in the primary and secondary schools, and gradually promoting programming education, encouraging social forces to participate in educational programming software, game development and promotion. Artificial intelligence education has been mentioned as a key development location. This indicates that artificial intelligence has risen to the national strategic level, and the deep integration of "artificial intelligence + education" has been opened. In this context, the Ministry of Education has carried out reform measures for artificial intelligence education. As early as 2014, the Ministry of Education fully implemented the revision of the general high school curriculum and curriculum standards (experiments), and required the core literacy of the discipline to be reflected in the revised principles and revised results. In the revision process of this high school information technology textbook, the changes in artificial intelligence textbooks are particularly large, mainly due to the development of the field in the past two years, and the resulting changes in a series of national policy guidelines. The revision of this artificial intelligence textbook is to integrate computational thinking as the main subject thinking into the core literacy design.

Computational thinking reflects the intrinsic value of artificial intelligence curriculum and has become an important part of artificial intelligence teaching research. In March 2006, Prof. Zhou Yizhen from the Department of Computer Science at Carnegie Mellon University in the United States proposed that computational thinking is a series of thinking activities that cover the breadth of computer science, such as problem solving, system design, and human behavior understanding, using the basic concepts of computer science [1]. Zhang Xuejun believes that computational thinking can enable students to understand the information world in a multi-disciplinary perspective using the disciplinary thinking of information technology, to solve the outstanding problems of the enthusiasm of students in the current development of information technology curriculum, and to further promote the information technology curriculum, reform and restructuring [2]. Chen Kaiquan regards computational thinking as a learner's ability to solve problems, aiming at intelligent society to cultivate the transformation of students' information literacy [3]. The "High School Information Technology Curriculum Standard Revision” completed in 2016 clearly pointed out the importance of computational thinking for students to establish information literacy. How to integrate computational thinking as the main subject thinking into the core literacy design is the focus and direction of this revi- 
sion of artificial intelligence teaching materials.

Second is the orientation of artificial intelligence in the high school information technology discipline and its logical relationship between disciplines.

At present, many colleges and universities in China have been actively implementing the first-level discipline of artificial intelligence. However, in the basic education stage, there is still a lack of curriculum links for corresponding content. Over the years, artificial intelligence has not received much attention in basic education. From textbooks to teachers to related software and hardware facilities, development has been slow. This revision of the Ministry of Education textbooks takes the implementation of the fundamental tasks of Lideshu people as a guide, and in-depth summarizes the valuable experience of China's ordinary high school curriculum reform since the 21st century, fully draws on the outstanding achievements of international curriculum reform, and strives to put the curriculum and curriculum standards of ordinary high schools in China. It is revised into a programmatic teaching document that has both international advanced level and actual conditions in China, and builds a general high school curriculum system with Chinese characteristics. The entire revision process was completed in five years. Among them, the revision of artificial intelligence textbooks can be said to have been changing. One of the main reasons is that it has been affected by the development of artificial intelligence in recent years and the related policies that the country has continuously introduced. Second, the characteristics of the curriculum itself are determined.

With the increasing importance of the artificial intelligence discipline, the orientation of the artificial intelligence curriculum in the entire high school information education is also changing, and the nature of the curriculum has also changed from the original selective curriculum to selective compulsory. Figure 1 shows the new version of the high school information technology module dependency relationship and curriculum adaptation strategy map. It can be seen from the figure that the artificial intelligence course plays a link between "data and computing" and "analytic algorithm", and horizontally has a close relationship with the "data management and analysis" course. After all, big data and statistical analysis It is the basis for the development of artificial intelligence. The revision of this textbook textbook chose Python as the main programming language for the entire discipline. Because the local conditions, the experimental conditions of the school, the teachers and the specific conditions of the students are very different, the Python language is not the only choice. Other programming environments, including $\mathrm{C} / \mathrm{C}++$, JavaScript, Blockly, App Inventor, $\mathrm{R}$, etc., are also suitable, artificial intelligence programming language.

Third, high school artificial intelligence textbooks

The core concept of this revision of the textbook of the Ministry of Education is to build an evaluation system based on discipline literacy, promote learning innovation in the digital age, support the development of students' information literacy, and promote the individualized development of students. The core literacy of the discipline is the concentrated expression of the value of the subject's 


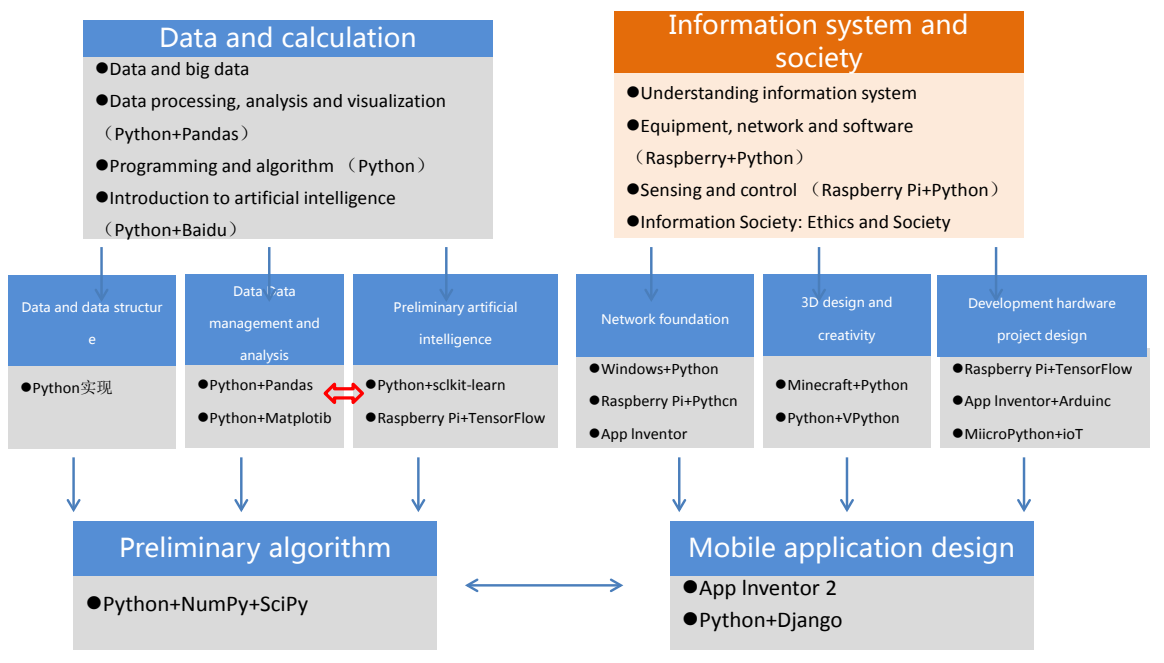

Figure 1. High school information technology discipline module dependency relationship and implementation strategy map.

education, and it is the correct value, the necessary character and the key ability gradually formed by the students through the study of the subject. The core literacy of high school information technology discipline consists of four core elements: information awareness, computational thinking, digital learning and innovation, and information society responsibility. They are the comprehensive expression of information technology knowledge and skills, processes and methods, emotional attitudes and values gradually formed by students in the process of receiving information technology education. Among them, computational thinking has certain particularities compared to the other three elements. Students with computational thinking can define problems, abstract features, establish structural models, and organize data rationally in information activities. By judging, analyzing, and synthesizing various information resources, reasonable algorithms are used to solve problems. Solution; summarize the process and method of solving problems using computers and migrate to other problem-solving related to them [4] [5].

\section{Construction of Artificial Intelligence Textbook Framework Based on Subject Literacy}

Based on the four core elements of the discipline, we designed the framework and style of artificial intelligence textbooks. Table 1 shows the basic framework of high school artificial intelligence textbooks based on the core literacy evaluation system. The basic framework of the new textbook is centered on the core literacy of the above four university departments, while taking into account the inheritance of the three-dimensional goals. The table shows the core literacy and three-dimensional goals of the first part of the textbook. The three-dimensional goal refers to the application of the corresponding knowledge and technology, the learning method through the learning process, and the cultivation of emotional attitudes and values. 
Table 1. Basic framework of artificial intelligence preliminary textbook.

\begin{tabular}{|c|c|c|c|c|c|c|c|c|}
\hline \multirow[b]{2}{*}{$\begin{array}{l}\text { Primary } \\
\text { directory }\end{array}$} & \multirow[b]{2}{*}{$\begin{array}{l}\text { Secondary } \\
\text { directory }\end{array}$} & \multicolumn{4}{|c|}{ Core literacy } & \multicolumn{3}{|c|}{ Three-dimensional target } \\
\hline & & $\begin{array}{l}\text { Information } \\
\text { Awareness }\end{array}$ & $\begin{array}{l}\text { Computing } \\
\text { Thinking }\end{array}$ & $\begin{array}{l}\text { Digital Learning } \\
\text { and Innovation }\end{array}$ & $\begin{array}{c}\text { Information } \\
\text { Social } \\
\text { Responsibility }\end{array}$ & Knowledge and skills & $\begin{array}{l}\text { Process and } \\
\text { methods }\end{array}$ & $\begin{array}{l}\text { Emotional attitudes } \\
\text { and values }\end{array}$ \\
\hline $\begin{array}{c}\text { Unit } 1 \\
\text { Understanding } \\
\text { artificial } \\
\text { intelligence }\end{array}$ & $\begin{array}{l}\text { 1.1 Artificial } \\
\text { intelligence } \\
\text { around the } \\
\text { task }\end{array}$ & $\begin{array}{l}\text { According to } \\
\text { the needs of } \\
\text { task activities, } \\
\text { consciously and } \\
\text { actively seek } \\
\text { appropriate } \\
\text { ways to obtain } \\
\text { and process } \\
\text { information. }\end{array}$ & $\begin{array}{l}\text { By judging, } \\
\text { analyzing and } \\
\text { synthesizing } \\
\text { various } \\
\text { information } \\
\text { resources to fill } \\
\text { in the activity } \\
\text { information } \\
\text { table, guide the } \\
\text { whole process } \\
\text { of the activity. }\end{array}$ & $\begin{array}{l}\text { Find the } \\
\text { information } \\
\text { you need and } \\
\text { use it to } \\
\text { conduct } \\
\text { self-learning } \\
\text { and } \\
\text { collaborative } \\
\text { learning. }\end{array}$ & $\begin{array}{l}\text { Obey the } \\
\text { network norms } \\
\text { and develop } \\
\text { good online } \\
\text { habits in the } \\
\text { process of } \\
\text { searching for } \\
\text { information } \\
\text { online. }\end{array}$ & $\begin{array}{l}\text { It can describe the basic } \\
\text { concepts and basic } \\
\text { characteristics of artificial } \\
\text { intelligence; know the } \\
\text { development history and } \\
\text { typical application of } \\
\text { artificial intelligence; } \\
\text { Discover artificial } \\
\text { intelligence of life change; } \\
\text { master the use of } \\
\text { common artificial } \\
\text { intelligence tools to } \\
\text { conduct writing learning }\end{array}$ & $\begin{array}{l}\text { According to the } \\
\text { theme, fill in the } \\
\text { activity record } \\
\text { form, and report } \\
\text { on the results. }\end{array}$ & $\begin{array}{l}\text { Deeply perceive the } \\
\text { impact of artificial } \\
\text { intelligence on life and } \\
\text { improve the ability to } \\
\text { comprehensively apply } \\
\text { information } \\
\text { technology. }\end{array}$ \\
\hline
\end{tabular}

The basic framework of the textbook is based on the four core literacy emphasized by the curriculum standards. At the same time, as a revised textbook, it takes into account the inheritance of the three-dimensional goal. Therefore, the design of the basic framework reflects the characteristics of inheritance and development. In this textbook, we will start from the aspects of understanding artificial intelligence, intelligent home system preliminary, intelligent robot design, understanding artificial intelligence technology, etc., and carry out classroom-based learning in the form of "project-task-activity". Mixed learning activities in digital learning and development practice. Through the hands-on construction and implementation of a simple intelligent system work scenario, understand the control structure and basic implementation principles of the intelligent system.

From the beginning of this revision, the artificial intelligence curriculum has been changed from the original high school information technology elective module to selective compulsory. The module content of this course is linked with the robot production competition activities, which is another way to cultivate innovative talents. In the course of course preparation, we also added the new case application in the field of artificial intelligence to enhance students' interest in learning, and stimulate students' curiosity through the analysis of the principles of common intelligent electronic devices, fully considering the cognitive characteristics of high school students, and choosing The AI application problems that are closely related to their study and life are visible and tangible as a case study.

\section{Textbook Content Standard Construction}

According to the latest curriculum standards of the Ministry of Education, the content standards of high school artificial intelligence textbooks are roughly as shown in Figure 2. It can be divided into three parts: artificial intelligence foundation, simple intelligent system development and artificial intelligence technology development and application. 


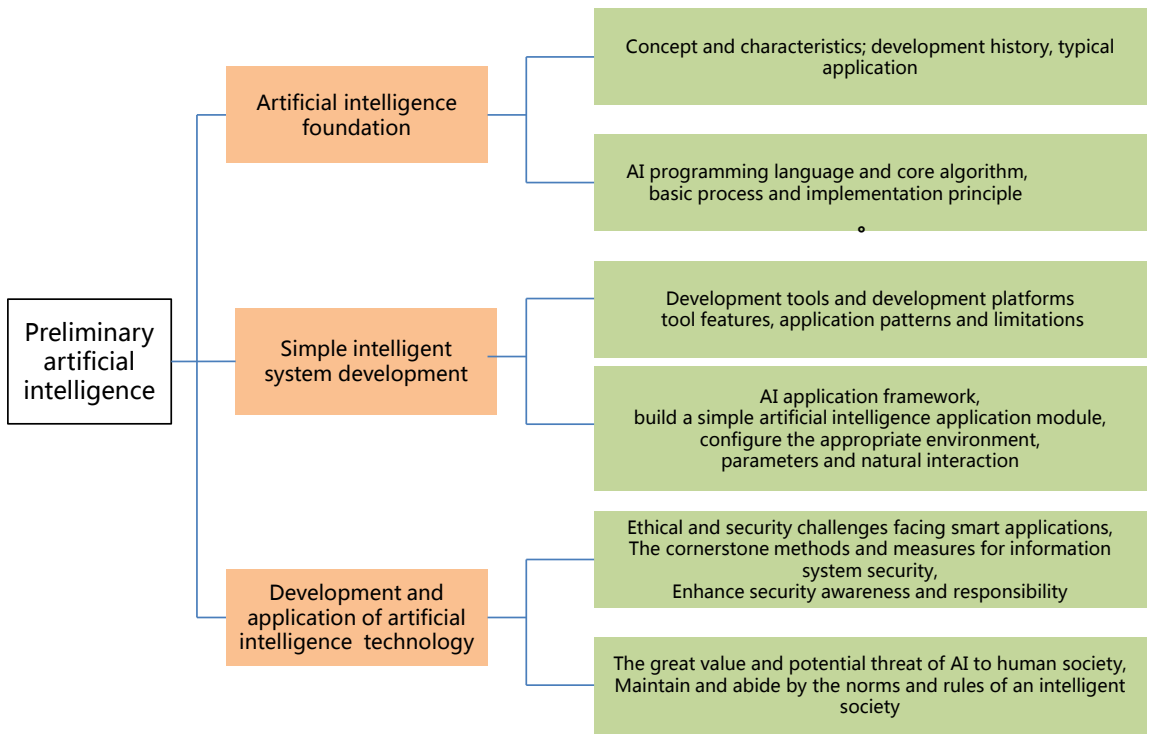

Figure 2. Standard structure diagram of artificial intelligence textbook content.

Among them, the basic part mainly includes the theoretical knowledge of artificial intelligence related concepts, characteristics, development history, typical application of artificial intelligence, as well as artificial intelligence programming language and core algorithm, artificial intelligence application to achieve the basic process and implementation principles and other technical content. In addition to introducing relevant development tools and development platforms, simple intelligent system development mainly describes artificial intelligence framework applications, simple artificial intelligence application module construction, environmental parameter configuration, and implementation of various natural interaction modes. The artificial intelligence technology development and application module mainly involves the ethical and security challenges faced by intelligent application systems, enhances the awareness of security protection and responsibility, and the great value and potential threat of artificial intelligence to human society, and guides students to maintain and abide by the norms of intelligent society, knowledge with the role.

\section{New and Old Textbook Comparison}

The new edition (2018 edition) textbooks are written strictly according to the "Ordinary High School Information Technology Curriculum Standards (2017 Edition)". The new and old curriculum standards vary greatly. Therefore, the new edition textbooks and the old edition (2004 edition) textbooks are quite different, and can be largely said to be rewriting the textbook. The obvious differences between the two in the textbook system are shown in the table (Table 2).

Specifically, the new and old versions of the textbooks have significant differences in content, layout, difficulty, and features. In order to carry out relatively complete and detailed analysis of textbooks, we have identified various indicators of textbook analysis, including content, layout, difficulty, and features. The indicators of each dimension are shown in Table 3 [6]. 
Table 2. Comparison of new and old teaching materials system.

\begin{tabular}{|c|c|}
\hline New textbook content catalogue system & Old textbook content catalogue system \\
\hline $\begin{array}{l}\text { Unit } 1 \text { recognizes artificial intelligence } \\
\text { 1.1 Artificial intelligence around you } \\
\text { 1.2 The main drivers of artificial intelligence } \\
\text { Unit } 2 \text { Intelligent Robot Preliminary } \\
\text { 2.1 Recognize and build intelligent robots } \\
\text { 2.2 Sensory and control of the robot } \\
\text { 2.3 Let the robot car drive intelligently } \\
\text { 2.4 Realizing the Obstacle Avoidance of Robot } \\
\text { Cars } \\
\text { 2.5 Realize remote interaction and control of } \\
\text { robot car } \\
\text { Unit } 3 \text { Simple Smart Home System } \\
\text { 3.1 Smart Home and Life } \\
\text { 3.2 Smart Home Green Lighting } \\
\text { 3.3 Smart home audio and air conditioning } \\
\text { 3.4 Simple smart home scene mode } \\
\text { 3.5 Intelligent Robot Manager } \\
\text { Unit } 4 \text { Artificial Intelligence Core Technology } \\
\text { 4.1 Machine Learning and Its Applications } \\
\text { 4.2 Understanding Artificial Neural Networks } \\
\text { Unit } 5 \text { The future of artificial intelligence } \\
\text { 5.1 The development direction of artificial } \\
\text { intelligence } \\
\text { 5.2 Potential value of artificial intelligence } \\
\text { 5.3 Artificial Intelligence challenges the legal } \\
\text { system and ethics }\end{array}$ & $\begin{array}{l}\text { Chapter } 1 \text { Getting to know artificial intelligence } \\
\text { 1.1 What is artificial intelligence? } \\
\text { 1.2 What can artificial intelligence do for us? } \\
\text { Chapter } 2 \text { Understanding Artificial Intelligence } \\
\text { Language } \\
\text { 2.1 Understanding Prolog } \\
\text { 2.2 Using Prolog } \\
\text { 2.3 Artificial Intelligence Language Chapter III } \\
\text { Representing Knowledge by Computer } \\
\text { 3.1 Knowledge and its type } \\
\text { 3.2 Introduction to Knowledge Representation } \\
\text { 3.3 Common methods of knowledge } \\
\text { representation } \\
\text { Chapter IV Using Computer Reasoning } \\
\text { 4.1 What is an expert system? } \\
\text { 4.2 How does the expert system work? } \\
\text { 4.3 How to develop an expert system } \\
\text { Chapter } 5 \text { Solving Problems with Smart Search } \\
\text { 5.1 Problems that can be solved by searching } \\
\text { 5.2 Blind search } \\
\text { 5.3 Heuristic search } \\
\text { Chapter VI Development and Future of } \\
\text { Artificial Intelligence } \\
\text { 6.1 Development of artificial intelligence } \\
\text { 6.2 The future of artificial intelligence }\end{array}$ \\
\hline
\end{tabular}

According to Table 3, we made a detailed comparison of the revision changes of the new and old textbooks of compulsory modules. Table 4 shows the changes in the content, layout, difficulty and characteristics of the new and old textbooks.

Third, integrate computational thinking as the main subject thinking into the core literacy design.

The current discussion of computational thinking around the world also provides ideas for our curriculum design. In-depth observation of the concept of computational thinking, it can be found that it comes from computer science, first used to describe the ideas and methods in computer science, and after moving towards a broader social vision, it gradually evolved into a "human" around the subject, becoming a The concept of the intrinsic quality of human beings derived from scientific thinking has led to a broader and important social and educational significance. In the process of textbook design, how to integrate computational thinking as the main subject thinking into the core literacy design, we mainly achieve through the following aspects.

1) Curriculum Design Based on Computational Thinking

There are different opinions at home and abroad on the definition of the framework of computational thinking. The mainstream view is mainly based on problem solving. The computational thinking in this research, high school information technology textbook, refers more to a series of thinking activities 
Table 3. Teaching material analysis indicators.

\begin{tabular}{|c|c|}
\hline Dimensional & textbook analysis indicators \\
\hline Content & $\begin{array}{l}\text { The content of the textbook is the carrier for the implementation of the } \\
\text { curriculum standards. The selection of the content and the organization of the } \\
\text { expression must follow the rules of human understanding of things and learning } \\
\text { cognition. The analysis of the content of the textbook is an analysis of the } \\
\text { coverage and extensibility of the textbooks for each knowledge point and } \\
\text { requirement in the curriculum standards. It can be from the capacity of the } \\
\text { textbook content, the core concepts involved in the textbook content, the focus } \\
\text { of the textbook content, and the main tools used in the textbook. Aspect analysis. }\end{array}$ \\
\hline Orchestration & $\begin{array}{l}\text { The layout of textbooks is an important factor in measuring the quality of } \\
\text { textbooks. The textbooks are applicable to students. Whether the layout is } \\
\text { suitable for students of the current age group to read and use is a problem that } \\
\text { textbook writers must consider. The textbook layout analysis can be extended } \\
\text { from the overall structure of the textbook (macro layer: the overall frame layout } \\
\text { of the textbook) and the layout of the text (middle layer: pointing to the overall } \\
\text { presentation of the content of each chapter of the textbook), and expanding the } \\
\text { arrangement of knowledge (micro layer : pointing to the presentation of } \\
\text { extended knowledge in the textbook), the arrangement of the exercises (micro } \\
\text { level: pointing to the presentation of the exercises in the textbook) and other } \\
\text { aspects. }\end{array}$ \\
\hline Difficulty & $\begin{array}{l}\text { The difficulty of the textbook is an important factor affecting the } \\
\text { implementation of the textbook. Textbooks are the carrier of teaching and } \\
\text { learning, and also the main front of teaching and learning. Therefore, it is } \\
\text { especially necessary to consider the difficulty in both teacher teaching and } \\
\text { student learning. }\end{array}$ \\
\hline Characteristic & $\begin{array}{l}\text { Textbooks must have certain characteristics when they are written. Whether the } \\
\text { textbooks conform to the development of the new era, whether it meets the } \\
\text { requirements for talent cultivation in the development of the state and society, } \\
\text { and whether it can reflect the characteristics of the discipline itself can be used as } \\
\text { the content of the analysis of the characteristics of the textbook. This set of } \\
\text { textbooks is mainly analyzed in terms of forward-looking, policy, operability, } \\
\text { scalability, and technical testing. }\end{array}$ \\
\hline
\end{tabular}

generated in the process of problem solving using computer science thoughts. The core view of Professor Li Yi's team on computational thinking is roughly the same: computational thinking can be understood as the thinking of information technology disciplines. In the information technology curriculum, computational thinking is expressed as six groups of equal and interrelated thinking themes, namely objects and management. Rules and safety, systems and engineering, design and production, collaboration and collaboration, ethics and ethics. These six sets of questions are formed during the problem-solving process and are a set of thinking methods and values for thinking and solving problems. [7] Based on the perspective of Professor Li Yi's team, Dr. Yu Ying constructed the triangulation structure of the computational thinking of information technology courses based on the computational thinking structure, [8] as shown in the following figure (Figure 3).

This textbook confirms its meaning, starting from here, and regards it as the main part of the core literacy of information technology. On this basis, we regard computational thinking as a "disciplinary thinking" for core literacy 
Table 4. Comparison of new and old teaching materials.

\begin{tabular}{|c|c|}
\hline Dimensional & Dimensional textbook revision change \\
\hline Content & $\begin{array}{l}\text { 1) Capacity: There are } 6 \text { chapters in the old textbook; the new textbook is compiled } \\
\text { into } 5 \text { chapters. } \\
\text { 2) Core concept: The core concepts of the old textbooks mainly include } \\
\text { knowledge representation, reasoning, expert system, search, etc. The core concepts } \\
\text { of the new textbooks mainly include intelligent systems, artificial neural networks, } \\
\text { and machine learning. } \\
\text { 3) Key points: The old textbook focuses on the experience of the expert system; the } \\
\text { new textbook focuses on the analysis and design of the intelligent system. } \\
\text { 4) Tools: The old version of the textbook uses the prolog language; the new version } \\
\text { of the textbook uses the python language, using pcduino hardware for intelligent } \\
\text { system tasks and activities. }\end{array}$ \\
\hline Orchestration & $\begin{array}{l}\text { 1) The overall structure: the old version of the textbook is based on the } \\
\text { knowledge system of artificial intelligence; the new version of the textbook is based } \\
\text { on the application of the intelligent system. } \\
\text { 2) The layout of the text: The old version of the textbook is arranged in a schematic } \\
\text { diagram of the explanation of the operation steps; the new version of the textbook } \\
\text { constitutes the artificial intelligence knowledge system with the physical diagram of } \\
\text { the intelligent hardware, the intelligent system flow chart and the program code. } \\
\text { 3) Expanding the arrangement of knowledge: The old version of the textbook is } \\
\text { only a supplement to the fragmented knowledge of artificial intelligence; the new } \\
\text { version of the textbook focuses on mining the latest developments in artificial } \\
\text { intelligence. } \\
\text { 4) The arrangement of the exercises: The old version carries out the shallow expe- } \\
\text { rience of artificial intelligence through comprehensive practice; the } \\
\text { expansion practice of each chapter of the new edition of the textbook pays atten- } \\
\text { tion to the relatively complete design and practice process and } \\
\text { experiences the intelligent system. }\end{array}$ \\
\hline Difficulty & $\begin{array}{l}\text { 1) Learning difficulty is different: the old version of the textbook is more } \\
\text { focused on the theory of the expert system, more abstract; the new version of the } \\
\text { textbook through the introduction of smart home and other examples, students get } \\
\text { easier and more intuitive, more conducive to stimulate students' interest. } \\
\text { 2) The difficulty of teaching implementation is different: in the old textbooks, the } \\
\text { acquisition of teaching resources such as the expert system is more } \\
\text { difficult; in the new edition of the textbook, the open source software and hardware } \\
\text { such as smart home are rich in teaching resources and easy to obtain. }\end{array}$ \\
\hline Characteristic & $\begin{array}{l}\text { 1) Reflecting forward-looking: Tracking the frontiers and typical application cases } \\
\text { of artificial intelligence development. } \\
\text { 2) Reflecting policy: embodying the organic connection between artificial } \\
\text { intelligence and basic education, and implementing the policy spirit of the State } \\
\text { Council's "New Generation Artificial Intelligence Development Plan." } \\
\text { 3) Embody operability: This module implements the basic knowledge of artificial } \\
\text { intelligence and the application experience of intelligent system with } \\
\text { project-task-activity. Students can not only master the basic knowledge, but also } \\
\text { gain first-hand experience knowledge through personal practice. Simple } \\
\text { intelligent technology application module, experience the basic process and } \\
\text { method of designing and implementing simple intelligent system, and enhance the } \\
\text { sense of responsibility of using intelligent technology to serve human } \\
\text { development. } \\
\text { 4) Embodying extensibility: In addition to the basic knowledge and basic } \\
\text { operation ability, this module also has special expansion exercises, which may } \\
\text { allow students to learn from the basic knowledge and skills of the classroom, and } \\
\text { also expand their exercises through extracurricular activities. And the } \\
\text { improvement and expansion of capabilities. }\end{array}$ \\
\hline
\end{tabular}




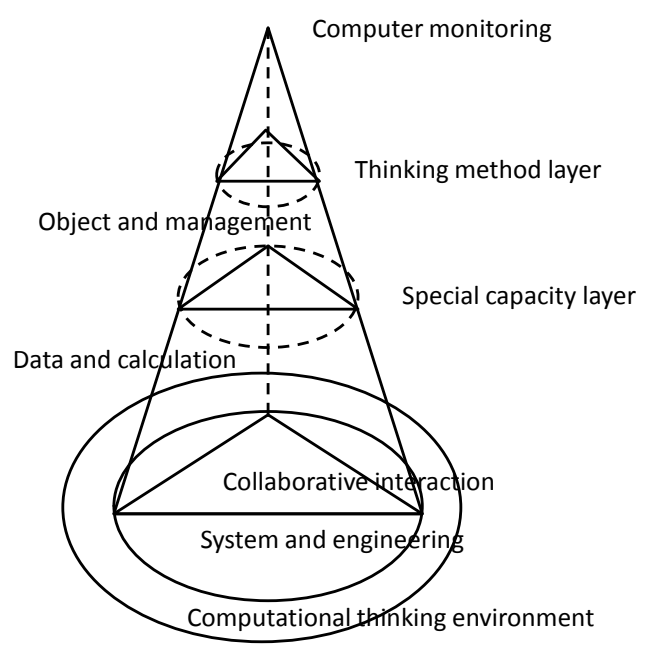

Figure 3. Information technology curriculum calculation thinking structure.

design, and distribute six parallel and related thinking categories to different modules of the textbook.

Among the four core elements of the core literacy of high school information technology disciplines, computational thinking has certain uniqueness. Because the other three elements, namely information awareness, digital learning and innovation, and information social responsibility have certain universality, computational thinking has the most essential academic attribute identification due to the background of the digital age [9]. Based on the full implementation of the "Ordinary High School Information Technology Curriculum Standards (2017 Edition)", this set of textbooks has deepened the computational thinking that can reflect the characteristics of information technology courses. The artificial intelligence module is based on the compulsory module and is also the natural extension and expansion of the compulsory module. The theory and application of artificial intelligence will involve more complex algorithms (programming), industry big data and information system basic elements, which are more complicated to process or solve through artificial intelligence. The practical problem allows students to experience the information system development process. On this basis, the use of subject characteristics to deepen students' ability to design and implement solutions using computational thinking (especially abstract, modular, and decomposition methods). Emphasizing the cultivation of computational thinking in the core literacy of this discipline is also a supplement and enhancement of the compulsory module. For example, in the process of building a simple intelligent system, we first set up a main task, and then complete the disassembled multiple subtasks through the form of activities. In the process of completing the tasks, the students pass design, coding, testing, collaboration, etc. The learning method sequentially experiences the entire solution process based on computational thinking. As shown in Figure 4, the flow chart of the computational thinking solution process is built by building a simple 


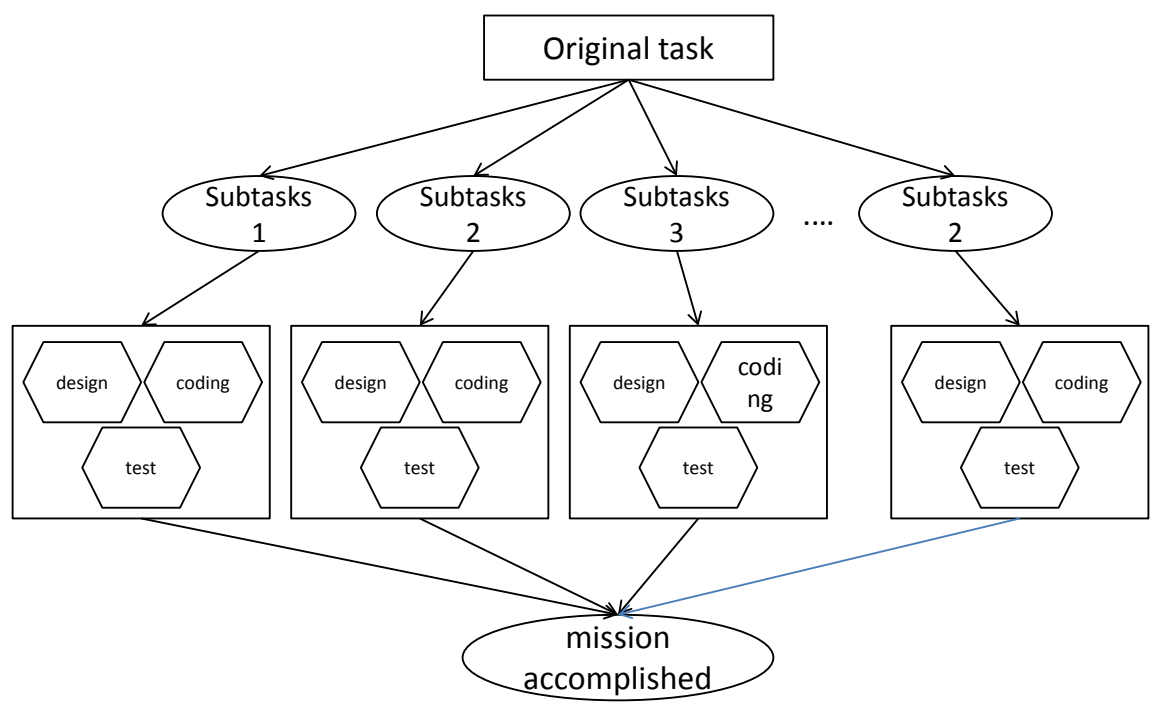

Figure 4. Computational thinking solution process by building a simple intelligent system.

intelligent system. This experience process also follows the structure design of the project-task-activity three-tier curriculum.

2) Based on the "project-task-activity" structure design.

For the first time, the textbooks included "project learning" and "student experiment" in the teaching of information technology subjects, emphasizing students' deep understanding of the principle content in hands-on experiments and promoting students' migration of experimental methods of information science. In the writing logic of the specific textbook content, the design is based on the "project-task-activity" structure. The structure revolves around the planning and validation of the project and a series of activities are carried out through the completion of the project tasks. Among them, the project and tasks are mainly located in "his main", while the "activities" are mainly located in "my master". Activities are oriented to the learning process. The formation of knowledge, the development of thinking, and even the formation of core literacy are naturally generated around activities in specific situations. Therefore, the framework of the textbooks around the structure is clear and relaxed, which is conducive to students' understanding of the multiple experiences of problem-solving activities and the different levels of disciplinary thinking, and gradually form and develop the core literacy of the discipline. In short, the "project-task-activity" structure is not a static structure, it reflects the process of student knowledge construction and thinking generation.

The textbook is designed based on the "project-task-activity" structure, which is organized around the planning and validation of the project, and a series of activities are carried out through the completion of the project tasks. The rhythm of the whole book framework around the structure is clear and relaxed, which is conducive to students' understanding of the multiple experiences of problem-solving activities and the different levels of disciplinary thinking, and 
gradually form and develop the core literacy of the discipline. The items in the textbook mainly describe the situation of the real problem. The task mainly describes the steps of the students' learning. The activity mainly describes the process of student practice. This kind of "project-task-activity" structure is not only conducive to assisting teachers to carry out classroom teaching reform, but also It is conducive to the development of students' self-exploration, cooperative learning and other in-depth learning skills. Figure 5 shows the design process of the teaching project based on the "project-task-activity" structure. For each of the key concepts in the course, we complete the entire project through steps such as task design, activity implementation, and results testing.

3) A new generation of artificial intelligence preferred programming language Python enhances the fusion of computational thinking

In the past two years, the usage of the Python language has been promoted to the forefront of all programming languages, and has become the preferred programming language for a new generation of artificial intelligence. In addition to the ease of use of the language itself, the main reason is that many mature labors have been developed based on Python. Intelligent (especially machine learning) application framework/platform. Such as scikit-learn (Python Machine Learning Extension Library), BATK (Baidu, Ali, Tencent, KedaXunfei) artificial intelligence application development platform, TensorFlow deep learning extension library (Google), Keras machine learning front-end interface and Ipython/Jupyter Notebook interactive front-end interface and more. These frameworks/platforms have accumulated a large amount of resources that can be used for teaching, and the contents required by this module can be implemented relatively easily. Figure 6 shows the programming environment structure of Python. In addition to the professional extension libraries mentioned above, there are Pandas (data processing module), SymPy (symbol computing module), Matplotlib (drawing module), NumPy/SciPy (numerical calculation module). Basic extension libraries. In the implementation of teaching, Python is the core programming language, supplemented by appropriate artificial intelligence/machine learning framework/platform to build the programming environment, not only let students understand the latest development of artificial intelligence technology, but also master the practical application skills. These practical open source platforms and interfaces not only improve the integration of computational thinking, but also make students aware of the importance of the intelligent era, platform and collaboration.

\section{Summary}

Integrating the concept of computational thinking into artificial intelligence teaching is a new way of teaching students' thinking. The textbook high school artificial intelligence textbook will soon be put into use. Under the framework of the textbook standard of the Ministry of Education of China, this set of textbooks subtly integrates the thinking mode and skill cultivation of the intelligent 


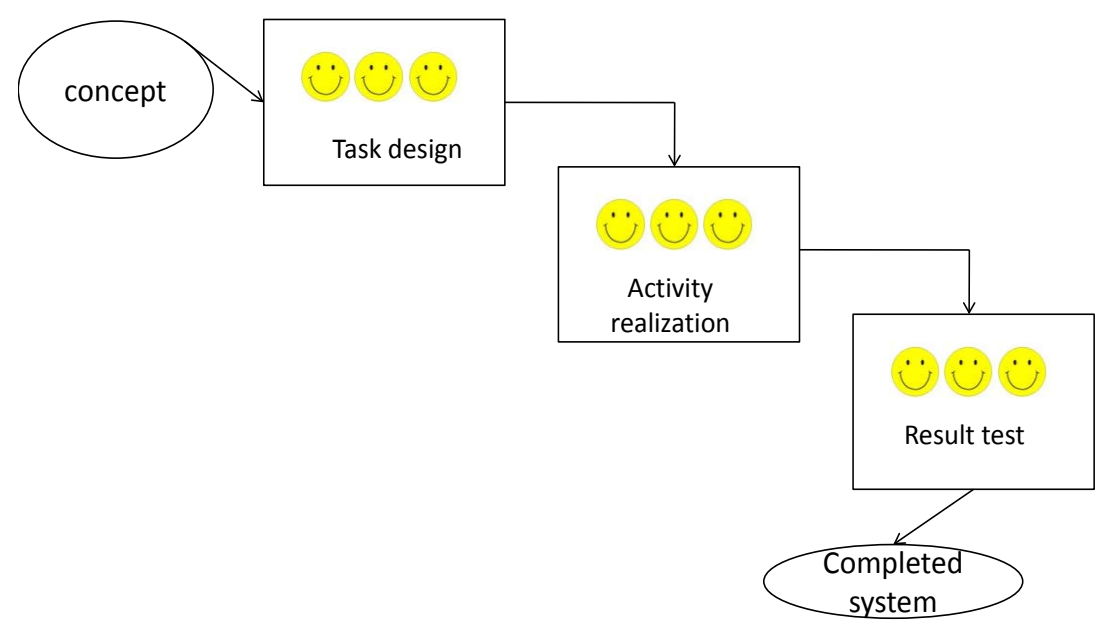

Figure 5. Teaching project design process based on the "project-task-activity" structure.

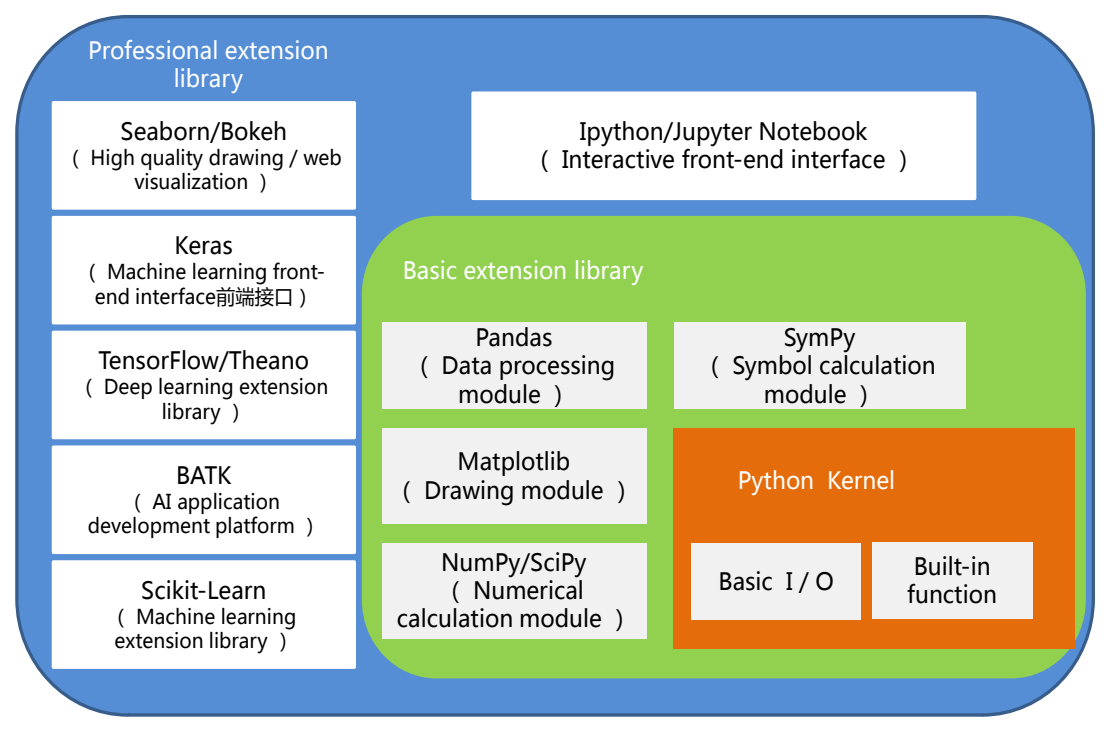

Figure 6. Structure of the Python programming environment.

era around the connotation, value, training strategy and teaching mode of computational thinking and Course design. Despite this, it is difficult to truly realize the basic education of artificial intelligence by relying on a set of teaching materials alone. A series of corresponding research and supporting facilities are also needed, such as the cultivation of artificial intelligence education teaching teams, the connection of computational thinking education at different stages, and how to face the knowledge of rapid update. The rapid development of knowledge in the intelligent era, from the teaching and learning is faced with the continuous updating of knowledge and thinking, which is particularly challenging for the improvement of the quality of the teaching team. In the era of intelligence, the future has come. Our education is not only the teaching of artificial intelligence technology, but also the cultivation of thinking patterns and skills in the intelligent age. 


\section{Funding}

2017-2018 Zhejiang University Major Humanities and Social Sciences Research Project "Application Research of Computational Thinking in the Teaching Design of Artificial Intelligence Course (Project No.: 2018QN054)".

\section{Conflicts of Interest}

The authors declare no conflicts of interest regarding the publication of this paper.

\section{References}

[1] Zhou, Y.Z. (2007) Computational Thinking. Academic Department of China Association of Science and Technology Association. New Views, New Theory, Academic Salon, Collection 7: Educational Innovation and Innovative Talent Cultivation. Academic Department of China Association of Science and Technology Association, 6 .

[2] Zhang, X.J., Guo, M.T. and Li, H. (2015) Analysis of Computational Thinking in the Information Technology Course of Senior Middle School. Journal of Electrotechnical Education, 36, 80-86.

[3] Chen, K.Q., He, Y. and Zhong, G.Q. (2018) The Information Literacy Connotation Transformation and the Orientation of AI Education in the Perspective of Artificial Intelligence: Also on the AI Curriculum and Teaching Implementation Path in the Basic Education Stage. Journal of Distance Education, 36, 61-71.

[4] Li, Y. and Zhong, B.C. (2016) Discussion on the Design of Core Literacy System for Information Technology Courses. Research of Audio-Visual Education, No. 4, 5-10.

[5] Li, Y. and Zhong, B.C. (2015) On “Core Literacy". Educational Research, No. 9, $17-24$.

[6] Lu, Y.R., Zhao, L. and Ren, Y.Q. (2016) An Analysis of the Status Quo of Information Ethics Education in Senior High Schools: A Comparative Study of the Textbooks of Information Technology Foundation in China from an International Perspective. China Electro-Chemical Education, No. 2, 88-93.

[7] Zhong, B.C. and Li, Y. (2016) The Scientific Meaning and Social Value Analysis of Computational Thinking. Jianghan Academic Journal, 35, 88-97.

[8] Yu, Y. (2017) Research on the Structure Design of High School Information Technology Teaching Materials Led by Computational Thinking. Northeast Normal University, 44-50.

[9] Sirje, P., Rea, R., Airi, K., Kerli, M. and Kaie, R. (2014) Students' Interpretations of the 6th Grade Science Textbook Design. Procedia-Social and Behavioral Sciences, $112,861-872$. 